\title{
Treatment challenges for men with eating disorders
}

$\mathrm{M}$

en with eating disorders have far more treatment options than a decade ago but their needs still go largely unaddressed in what remains a female-centric realm. That's cause for concern, warn experts on eating disorders, especially considering the difficulty of getting men into treatment in the first place.

"There is already enormous stigma for having something that is considered a 'female problem'," says Tom Wooldridge, assistant professor of psychology at Golden Gate University in San Francisco, California.

Though research over the past decade indicates men account for a quarter of cases of eating disorders such as anorexia nervosa and bulimia — far more than previously believed treatment is still largely geared toward women. In fact, it even exists at the diagnosis stage. Among the factors identified as possible indicators of an eating disorder, for example, is irregular menstruation.

The traditional format of treatment programs may also be ill suited for men. Therapy often takes place in a group setting, in which women typically outnumber men by a wide margin. It's no stretch to propose that an 18year-old male with anorexia would be reluctant to share his fears and insecurities in such an environment. After all, it's not as though boys are frequently encouraged to reflect upon their emotional well-being.

"Males are taught to repress their feelings to the point where they have difficulty even identifying what they are feeling," says Merryl Bear, director of the National Eating Disorder Information Centre, a nonprofit organization based in Toronto, Ontario. "So much of it has to do with how we manage our emotions and how we solve our problems. If we displace our emotions and problems onto our bodies, we are more likely to be at risk of harmful behaviours."

Discussions in group sessions dominated by women can also veer into terri-

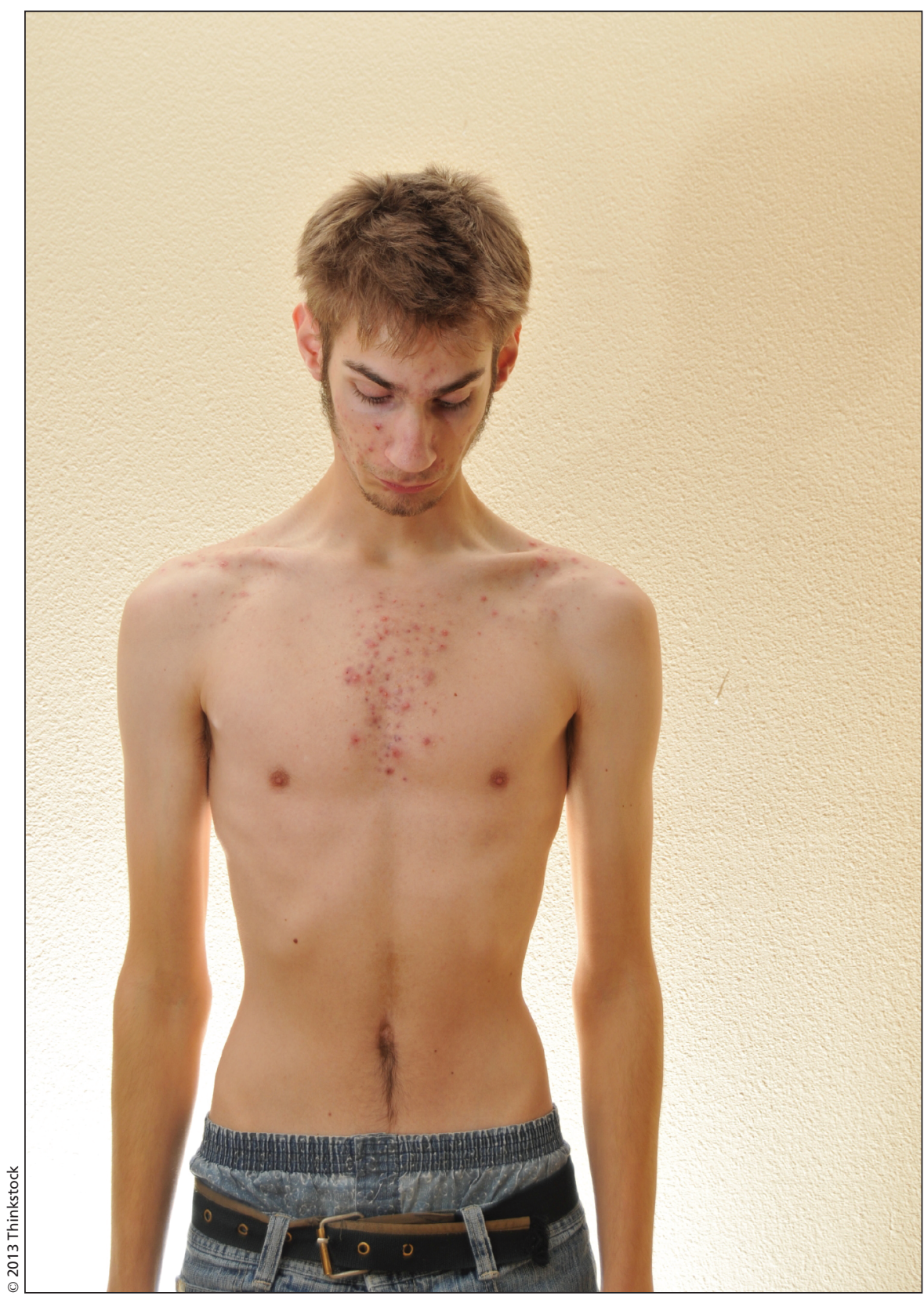

Men with eating disorders often delay seeking treatment until their cases are severe.

tory foreign to men, focusing on subjects such as missed menstrual periods and distorted body images attributed to waif-like models in fashion magazines. The clinicians in charge likely have little experience working with male patients. Some men in treatment have even suggested there was a feminist bent to the group sessions they attended, making them feel more like intruders than confidants.

"It is really common for men to feel very alienated," says Wooldridge, who writes about male eating problems on his blog The Forgotten Gender (www.psychologytoday.com/blog/the -forgotten-gender). "If it involves groups, they are likely to be the only male." 
The majority of the physical and psychological problems associated with eating disorders, however, are similar for both genders. So the solution to ineffective engagement of men probably lies in modifying existing programs, rather than coming up with something brand new, suggests Wooldridge. "I'm not convinced we need entirely different treatment models, but we could develop a way of speaking to men that acknowledges the differences - to help in understanding the experience of what it's like to be a man with this disorder."

Indeed, this appears to be one of the guiding tenets at Rogers Memorial Hospital in Oconomowoc, Wisconsin, which offers an eating disorder program exclusively for men. "You have to facilitate a level of comfort for men. That seems to be an important thing," says Dr. Ted Weltzin, medical director of eating disorder services.

One issue that does appear more frequently in men with eating disorders is "problematic exercising." Whereas women primarily desire lean bodies, men often want to be muscular as well. As many as half of male patients exercise compulsively - some to the point where they do further harm to their already malnourished bodies, says Weltzin. In 2007, for instance, a 22-year- old from Michigan named Thomas Lee Warschefsky died after his heart failed during his daily set of 1000 sit-ups. He weighed 35 kilograms at the time.

"The exercise becomes compulsive," says Weltzin. "They feel they have to do it. They typically feel stress and anxiety if they think they haven't exercised frequently enough. People will talk about it as an addictive type of thing. Exercise is a healthy activity, but at some point it becomes a consuming commitment."

Of course, gaining a better understanding of problematic exercise and other issues facing men with eating disorders won't result in clinical benefits if those men don't seek treatment. The number of men in therapy has risen but it still doesn't reflect the size of the male population with eating disorders. Though there is one subset that is more open to seeking help: homosexual men.

"Gay men have had to pay closer attention to their bodies and what's going on with their bodies," says David Brennan, assistant professor in the FactorInwentash Faculty of Social Work at the University of Toronto in Ontario. "Most gay men have engaged with the health care system and don't generally avoid it."

In fact, this may be another reason why heterosexual men avoid seeking treatment for eating disorders. They might fear being perceived as homosexual.
Another reason men have traditionally been poorly represented in treatment facilities has nothing to do with stigma, ignorance or denial. It's the issue of who pays for treatment. This can be particularly contentious in a country such as the United States, which doesn't have a publicly funded health care system.

"Insurance companies were holding the line that men didn't get eating disorders," says Leigh Cohn, author of Making Weight: Men's Conflicts with Food, Weight, Shape \& Appearance. "They would fight the diagnosis, which made it difficult for treatment facilities to get paid for treating males."

By raising public awareness about male eating disorders, experts in the field hope the barriers to treatment will diminish. Then men might be willing to seek help earlier, rather than waiting until their disorders advance to dangerous levels. "I would also say it's important to take male eating disorders very seriously when it comes to treatment because they have more severe cases when they start treatment," says Dr. Anu Raevuori, a postdoctoral research fellow in the department of public health at the University of Helsinki in Finland. "They have been sicker for a longer time." - Roger Collier, CMAJ

CMAJ 2013. DOI:10.1503/cmaj.109-4363 